\title{
External pH: An Environmental Signal That Helps to Rationalize pel Gene Duplication in Erwinia chrysanthemi
}

\author{
Laurence Nachin and Frédéric Barras \\ Laboratoire de Chimie Bactérienne, CNRS, IBSM, 31 Chemin Joseph Aiguier, 13402 Marseille Cedex 20, \\ France \\ Accepted 26 April 2000.
}

\begin{abstract}
The phytopathogenic bacterium Erwinia chrysanthemi produces five major pectate lyases that are key virulence factors in soft-rot disease development. Using transcriptional fusions, we studied the regulation of pelA, pelD, and pelE gene expression as a function of variation of the external pH. pelA and pelD were expressed when bacteria were grown in an acidic medium while pelE was transcribed only in basic medium. Using phenol red, we observed that, in chicory leaves, $\mathrm{pH}$ value of infected tissue varies from acidic to basic. Taken together, these findings are discussed in the context of a model unifying both catalysis and regulation to account for pel gene evolution. In particular, we propose that the three isoenzymes are produced sequentially during the infection process.
\end{abstract}

Additional keywords: plant pathogen.

Erwinia chrysanthemi is a gram-negative, plant-pathogenic bacterium that causes soft-rot symptoms on a great variety of plants (Barras et al. 1994; Perombelon and Kelman 1980). Secretion of pectinases and cellulase, iron assimilation, motility, and anti-oxidant systems appear to contribute to various extents to the virulence of E. chrysanthemi (Barras et al. 1994; El Hassouni et al. 1999; Franza and Expert 1991; Masclaux and Expert 1995; Py et al. 1998, 1999; López-Solanilla et al. 1998).

The E. chrysanthemi strain 3937 secretes five major pectate lyases. The cognate structural genes, referred to as pel, are organized in two clusters separated on the chromosome: pelA, pelE, and pelD; and pelB and pelC. Each cluster is believed to have resulted from successive rounds of duplication, since pel genes belonging to the same cluster share extensive sequence similarity and are directly adjacent one to the other (Barras et al. 1987; Reverchon et al. 1986). The advantage to E. chrysanthemi of maintaining such a number of highly related genes has been the object of speculation for some time.

Two non-mutually-exclusive hypotheses were put forward in attempts to rationalize pel gene duplication within each

Corresponding author: Frédéric Barras; Mailing address: Laboratoire de Chimie Bactérienne, CNRS, IBSM, 31 Chemin Joseph Aiguier, 13402 Marseille Cedex 20, France; Telephone: (33) 4911645 79; Fax: (33) 4 917189 14; E-mail: barras@ibsm.cnrs-mrs.fr cluster. (i) The catalysis hypothesis is that duplication events yielded an increased pectinolytic repertoire: duplication could have been followed by slight modifications of the genes, which would have led to an increased catalytic diversity of the cognate enzymes. This is consistent with early investigations that revealed differences among the isoenzymes in their capacities to macerate plant tissues, i.e., PelD and PelE are the most effective while PelA is unable to efficiently macerate plant tissues but was shown to be critical in soft-rot symptom development (Barras et al. 1987; Boccara et al. 1988; Beaulieu et al. 1992). Moreover, the end products generated from polygalacturonic acid (PGA) by each isoenzyme are different: PelE produced mainly dimers of oligogalacturonate whereas PelA action resulted in formation of di- to dodecamer fragments (Preston et al. 1992; Preston and Rice 1991; Roy et al. 1999). (ii) The regulation hypothesis postulates that the modifications that occurred after duplication had allowed the regulatory region to evolve such that each pel gene would be activated at a specific time point and/or in a specific environment during the infection. This is consistent with the fact that, despite being directly repeated, the pel genes constitute monocistronic units. In favor of such a hypothesis is the finding that high osmolarity decreased pelD but increased pelE transcription and had no influence on the expression of pelA (Hugouvieux-Cotte-Pattat et al. 1992). However, to date, the prevailing trend emerging from numerous regulation studies is that all pel genes are subject to the same regulatory molecular circuits and respond similarly to a given environmental signal (Hugouvieux-Cotte-Pattat et al. 1996).

When E. chrysanthemi infects a plant, it colonizes intercellular apoplastic fluid, the $\mathrm{pH}$ value of which is believed to lie between 5.0 and 6.5 (Grignon and Sentenac 1991). Upon colonization, bacteria induce cell lysis, which is likely to result in variation of the $\mathrm{pH}$ value of the intercellular environment. Surprisingly, the influence of external $\mathrm{pH}$ changes on Pel synthesis has not been investigated. In this work, we report that pelA, pelE, and pelD gene expression responds differently to $\mathrm{pH}$ changes, providing a rationale for understanding the ecological advantage of the pel redundancy.

We used E. chrysanthemi 3937 strain derivatives A1888, A1798, and A1828 (kindly provided by N. Hugouvieux-CottePattat), which contain pelA::uidA, pelD::uidA, and pelE::uidA 
chromosomal transcriptional fusions, respectively (Hugouvieux-Cotte-Pattat et al. 1996). Cells were grown in Ceria medium $\left(\mathrm{KH}_{2} \mathrm{PO}_{4} 8.5 \mathrm{~g} /\right.$ liter, $\left(\mathrm{NH}_{4}\right)_{2} \mathrm{SO}_{4} 1 \mathrm{~g} /$ liter, Na-citrate $0.5 \mathrm{~g} / \mathrm{liter}, \mathrm{MgSO}_{4} 0.1 \mathrm{~g} / \mathrm{liter}, \mathrm{MnSO}_{4} 10^{-6} \mathrm{M}, \mathrm{FeSO}_{4} 10^{-6} \mathrm{M}$ ) at $30^{\circ} \mathrm{C}$. Succinate and Casamino Acids were added at 2 and 1 $\mathrm{g} /$ liter, respectively. PGA was added at $4 \mathrm{~g} /$ liter to the medium. Kanamycin was added at a final concentration of 25 $\mu \mathrm{g} / \mathrm{ml}$. This medium was adjusted to appropriate $\mathrm{pH}$ by addition of $\mathrm{KOH}$.

$\beta$-Glucuronidase (GUS) activities associated with gene fusions were measured as follows: a $100-$ or $200-\mu \mathrm{l}$ aliquot of cells was mixed with $\mathrm{Z}$ buffer $\left(\mathrm{Na}_{2} \mathrm{HPO}_{4} 60 \mathrm{mM}, \mathrm{NaH}_{2} \mathrm{PO}_{4} 40\right.$ $\mathrm{mM}, \mathrm{KCl} 10 \mathrm{mM}, \mathrm{MgSO}_{4} \cdot 7 \mathrm{H}_{2} \mathrm{O} 1 \mathrm{mM}, \beta$-mercaptoethanol $50 \mathrm{mM}$; buffered at $\mathrm{pH} 7.0$ ) to produce a final volume of $1 \mathrm{ml}$ (Miller 1972). Cells were treated with one drop of chloroform and two drops of a $0.1 \%$ sodium dodecyl sulfate (SDS) solution. The mixture was vortexed and equilibrated at $37^{\circ} \mathrm{C}$ for 5 min before the assay was started by addition of a $200-\mu \mathrm{l}$ aliquot of $p$-nitrophenyl $\beta$-D-glucuronide $(4 \mathrm{mg} / \mathrm{ml})$. To stop the reaction, $500 \mu \mathrm{l}$ of $\mathrm{Na}_{2} \mathrm{CO}_{3} 1 \mathrm{M}$ was added. Cell debris were pelleted by centrifugation. The absorbance of the supernatant was measured at $405 \mathrm{~nm}$. The activities obtained were expressed in modified Miller units $\left(\mathrm{OD}_{405} \mathrm{~min}^{-1} \mathrm{ml}^{-1} \mathrm{OD}_{600}{ }^{-1}\right)$.

First, assays were conducted with overnight cultures grown in media adjusted initially to $\mathrm{pH}$ values of $5.5,6.0$, or 8.0. The results obtained indicated a $\mathrm{pH}$-dependent expression of pelA, pelD, and pelE genes (data not shown). pelA and pelD were better expressed when the bacteria were grown in acidic conditions ( $\mathrm{pH} 5.5$ or 6.0), whereas pelE expression was the highest when bacteria were in a more basic environment ( $\mathrm{pH} 8.0)$. In these experiments, the $\mathrm{pH}$ value of the medium increased during the growth, i.e., the value went up from 5.5 to $6.2,6.0$ to 6.6 , and 8.0 to 8.7. Therefore, expression of the pel genes and the extent of $\mathrm{pH}$ variation were both followed throughout the growth in media initially adjusted to either acidic or basic $\mathrm{pH}$ values (Fig. 1). In this case, the Ceria medium was inoculated at $\mathrm{OD}_{600} 0.1$ with an overnight culture grown at the $\mathrm{pH}$ value of the studied culture. We observed a slight and constant increase of $\mathrm{pH}$, but the difference of $\mathrm{pH}$ value between acidic and basic conditions remained constant during the growth (Fig. 1B). As expected, the activities corresponding to pelA and pelD expression were found to be the highest in acidic growth conditions, whereas pelE was mainly expressed when the bacteria were grown in basic conditions (Fig. 1C). At their optimum $\mathrm{pH}$, the level of pelD and pelE expression increased strongly between the beginning and the end of the exponential growth phase. The factor of increase was about fourfold for pelD and sixfold for pelE. In contrast, the level of pelA transcription was only 1.7 -fold higher at the end of the exponential growth phase at the optimum $\mathrm{pH}$, indicating that pelA expression was almost at its maximal level as soon as the bacteria were in an acidic environment.

The experiments reported above were performed in media containing PGA. This pectic-derived compound is degraded by $E$. chrysanthemi and the catabolic products mediate the induction of all the pel gene expression by preventing the $\mathrm{KdgR}$ repressor from binding on the operator sites (Hugouvieux-Cotte-Pattat et al. 1996). To test whether $\mathrm{pH}$ regulation was mediated by the $\mathrm{KdgR}$ repressor, the pelA or pelE::uidA fusions were transduced in the $k d g R$ mutant strain A837 and GUS activities were measured as described above, with cultures grown in Ceria medium at pH 5.5 or 8.0 (Fig. 2).
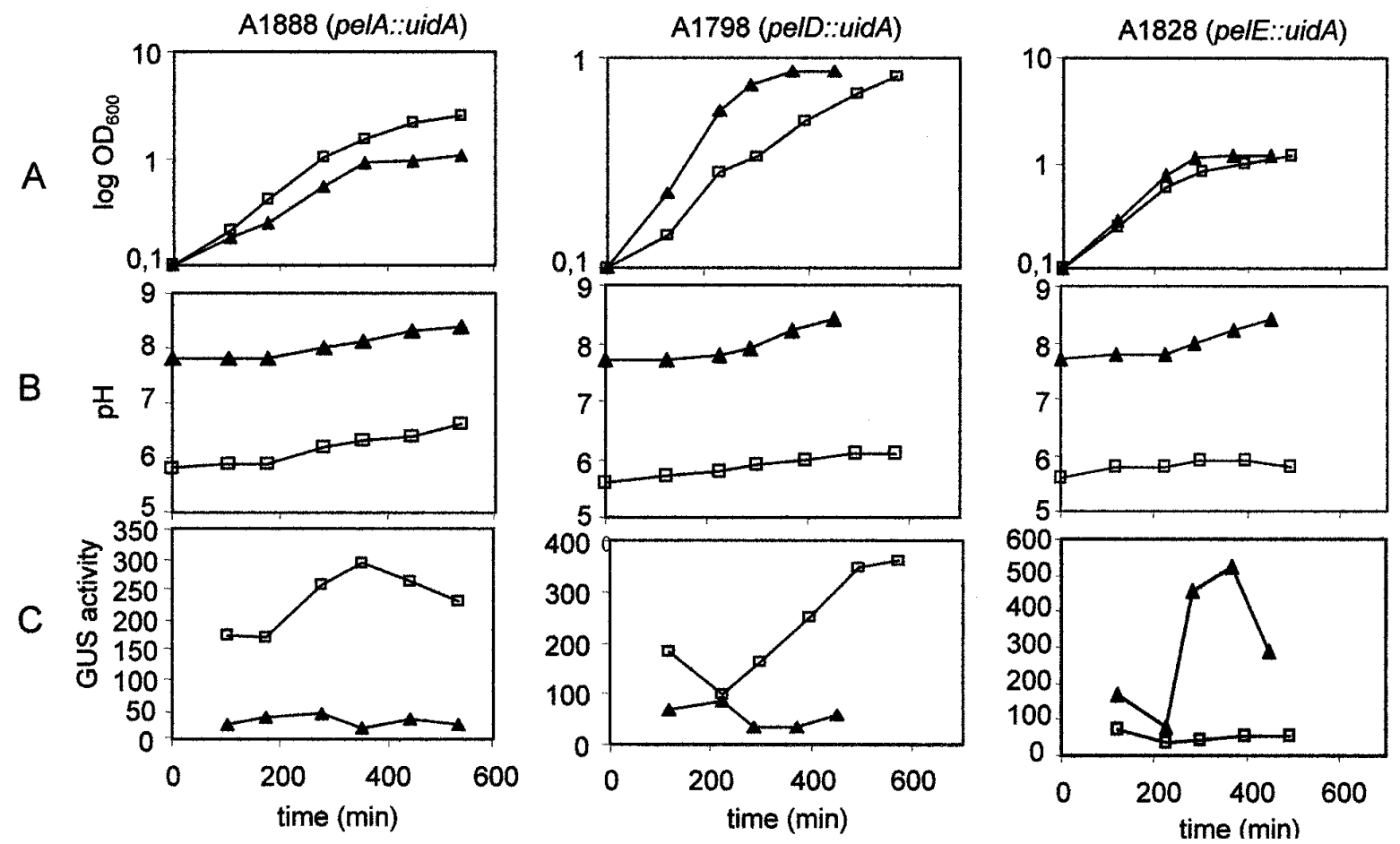

Fig. 1. A, Growth of the different strains in Ceria medium supplemented with polygalacturonic acid (PGA) was followed by measuring $\mathrm{OD}_{600}$. B, $\mathrm{pH}$ variation of the culture medium. C, Expression of the pel::uidA fusions in Erwinia chrysanthemi 3937 derivatives. $\beta$-Glucuronidase (GUS) activities of each strain were measured at indicated time points and expressed in modified Miller units. For each strain, three independent experiments were performed and results of a typical one are presented. $(\square)$ acid medium, ( $(\mathbf{\Lambda})$ basic medium (see text for details). 
In the $k d g R$ background, pelA and pelE expression was still activated in an acidic and basic medium, respectively, thereby demonstrating that $\mathrm{KdgR}$ is not mediating $\mathrm{pH}$ regulation. It is noteworthy that PGA induction required optimum $\mathrm{pH}$ to occur. We noticed that expression of pelE was not higher in the $k d g R$ background, as one would expect. Whether this relates to the existence of a $\mathrm{pH} 8.0$-mediated negative regulator requires further clarification. Another potential candidate regulator could be the PecS/PecM couple (Reverchon et al. 1994). These two proteins are thought to form a two-component regulatory system involved in pel gene regulation, yet the cognate environmental signal remains unknown. Each of the three pel fusions was transduced in a pecS mutant. Using cultures grown overnight, we still observed an expression of pelA and pelD only in acidic conditions and an expression of pelE in basic conditions (data not shown), thereby ruling out the involvement of the $\mathrm{PecS} / \mathrm{PecM}$ couple in the $\mathrm{pH}$ regulation. Last, we tested whether the Fur regulator, previously shown to regulate pel transcription in response to iron availability, was involved (Franza et al. 1998). Again, using the pelE::uidA fusion, we found no difference between wild type and the fur mutant strains (data not shown).
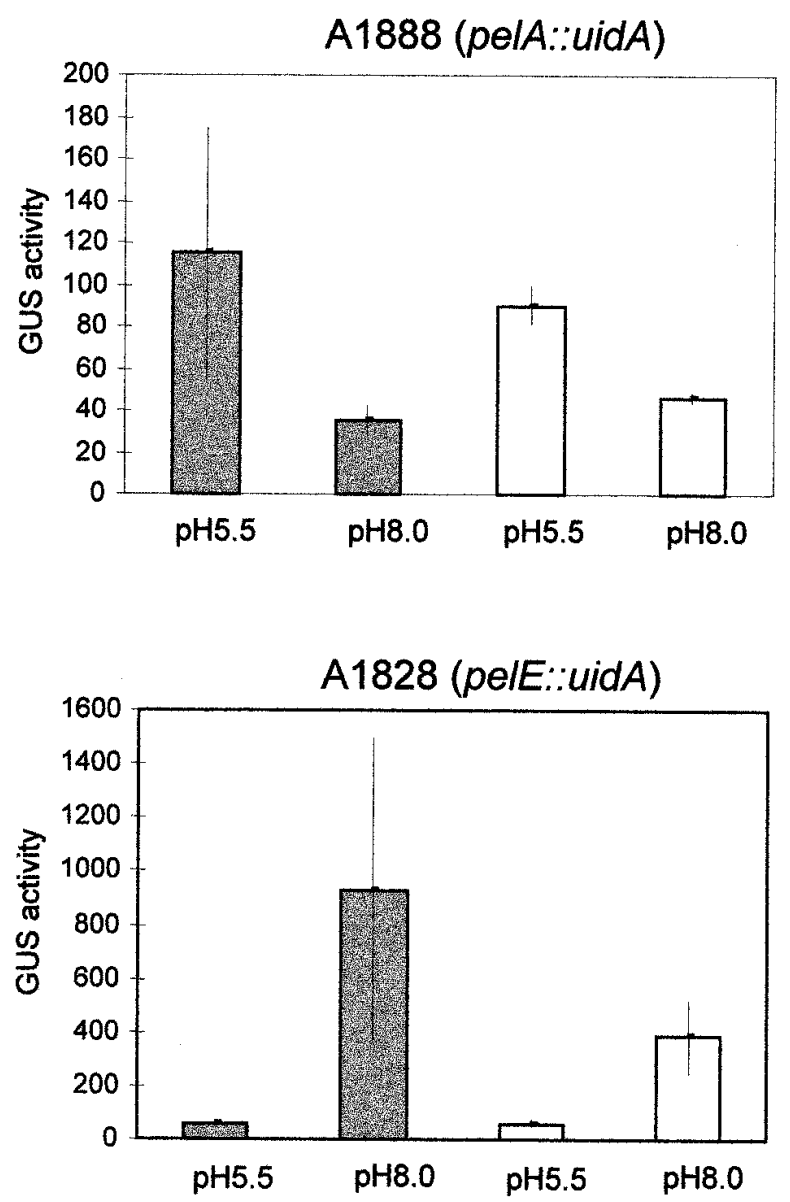

Fig. 2. Influence of a $k d g R$ mutation on the $\mathrm{pH}$-dependent expression of the pel::uidA fusions in Erwinia chrysanthemi 3937 derivatives. $\beta$ Glucuronidase (GUS) activities were measured with overnight cultures grown in Ceria medium supplemented with polygalacturonic acid (PGA) and expressed in modified Miller units. Values of the $\mathrm{pH}$ media are indicated. Shaded bars, wild type strain; open bars, $k d g R$ strain.
These results revealed a differential, $\mathrm{pH}$-dependent regulation of pelA, $D$, and $E$ genes: pelA and pelD are preferentially expressed in acidic conditions while pelE is mainly transcribed in basic condition. To determine whether a such regulation could occur in planta, we analyzed the $\mathrm{pH}$ variation in chicory leaves throughout the infection with a phenol red solution $(0.3 \%)$. This $\mathrm{pH}$ indicator is yellow at a $\mathrm{pH}$ value below 6.4 and red at a $\mathrm{pH}$ value above 8.2. Chicory leaves were cut on few millimeters long with a sterile scalpel and inoculated with $10^{5} \mathrm{CFU}$ of $E$. chrysanthemi 3937 from an overnight culture grown in rich medium. The chicory leaves were incubated at $30^{\circ} \mathrm{C}$ and one leaf was analyzed at different times of incubation by adding the phenol red solution at the inoculation site (Fig. 3). We observed a yellow color at the time of infection, indicating the $\mathrm{pH}$ value was acidic in the chicory leaves $(<6.4)$ (Fig. 3A). After $3 \mathrm{~h}$ of incubation, $\mathrm{pH}$ value was still acidic (Fig. 3B). An increase in the $\mathrm{pH}$ value was observed 6 $\mathrm{h}$ after infection, since the $\mathrm{pH}$ indicator turned red, while maceration symptoms were not as yet visible (Fig. 3C). After 9 and $24 \mathrm{~h}$ of incubation, tissue rotting occurred and we observed a red coloration of the phenol red, indicating the $\mathrm{pH}$ value of the infected tissue to be above 8.2 (Fig. 3D and E). The $\mathrm{pH}$ value was estimated to be between 8 and 9 with a $\mathrm{pH}$ paper soaked in the maceration area. These results showed a significant change in $\mathrm{pH}$ from acidic to basic value in plant tissues during the infection process.

Taken together these findings allow us to propose the following model wherein the Pels act sequentially during the infection. The environment encountered by E. chrysanthemi when invading the plant is at acid $\mathrm{pH}$ where pelA and pelD would be expressed. PelA and PelD are therefore likely to act in the early steps of the infection. Conversely, pelE could act in later stages of the infection when the medium surrounding E. chrysanthemi is alkaline. This proposal of a sequential mode of action of the Pels is consistent with a previous study of pel gene expression in planta by Masclaux et al. (1996), who observed that pelD was the first to be induced after infection.

PelD and PelE are highly related enzymes. Enzymological studies failed to reveal differences and these two isoenzymes seem to be produced at the same level (Hugouvieux-CottePattat et al. 1992; Reverchon and Robert-Baudouy 1987; Tardy et al. 1997). Hence, the fact that one is synthesized in the early stages of the infection and the other in later stages suggests that duplication allowed the bacterium to adapt to changing environment while keeping constant the level of this type of Pel isoenzyme, which has a great macerating power. PelA is distinct from the other Pels in that it exhibits a very poor macerating ability and seems always weakly produced. Nevertheless, mutation in the pelA gene resulted in symptoms delay, indicating a peculiar role of this isoenzyme in the infection process (Beaulieu et al. 1992). PelA was found to produce oligomers with a high degree of polymerization (DP). Such oligomers are known to activate plant defense systems and to induce a very rapid $\mathrm{H}^{+}$influx in plant cells, resulting in an increase of the $\mathrm{pH}$ of the apoplastic fluid (Baker et al. 1986, 1990). In such an alkaline medium, PelE, and possibly other Pels, which have stronger maceration capacity, will depolymerize pectin of the cell wall-generating oligomers of low DP, a more efficient carbon source for the growing bacteria. Hence, production of PelA as soon as the bacteria invade the 


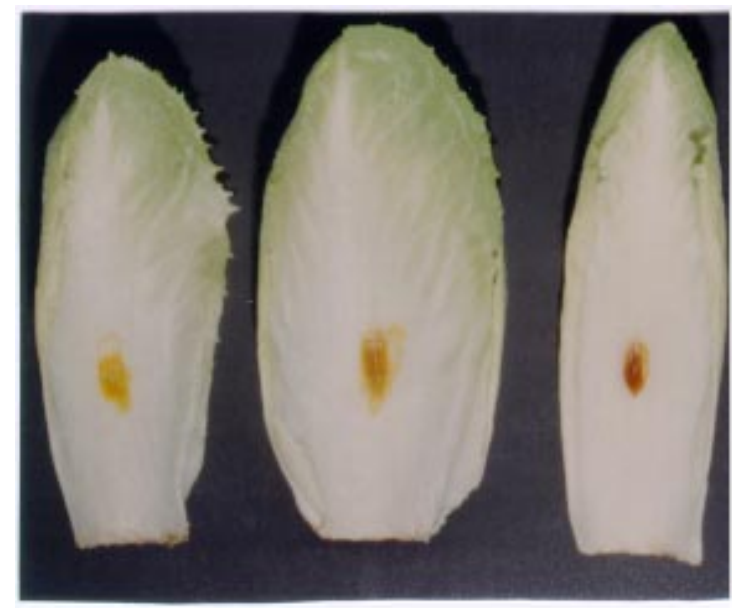

A
B

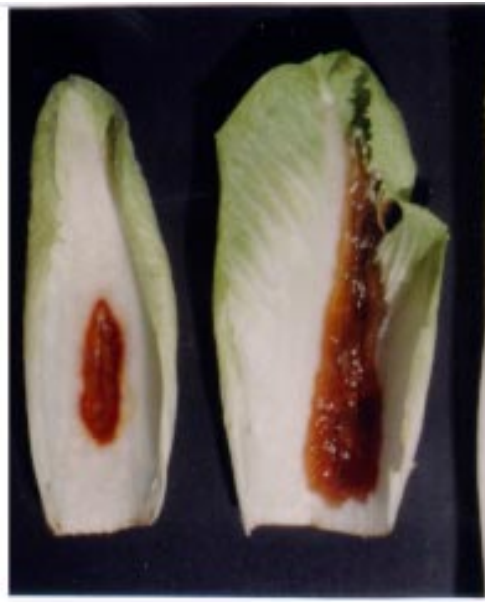

$E$

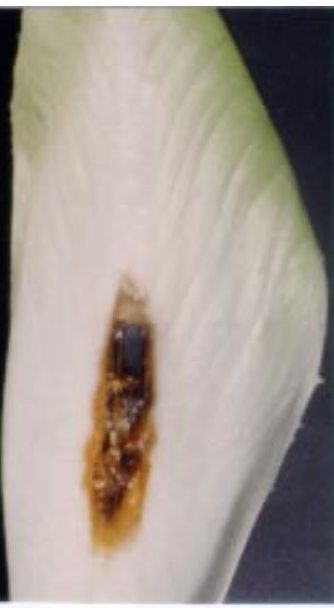

$\mathrm{F}$

Fig. 3. $\mathrm{pH}$ variation in plant tissues upon infection. Chicory leaves were inoculated with Erwinia chrysanthemi wild-type strain and incubated at $30^{\circ} \mathrm{C}$. Phenol red solution $(0.3 \%)$ was added at the wound site at $(\mathbf{A})$ time of inoculation, and after different times of incubation: $\mathbf{B}, 3 \mathrm{~h} ; \mathbf{C}, 6 \mathrm{~h} ; \mathbf{D}, 9 \mathrm{~h}$; and $\mathbf{E}$, $24 \mathrm{~h}$. The $\mathrm{pH}$ indicator was yellow at a $\mathrm{pH}$ value below 6.4 and turned red at a $\mathrm{pH}$ value above 8.2. Upon infection, $\mathrm{pH}$ value in infected chicory leaves increased from (A and $\mathbf{B}$ ) acidic to $(\mathbf{C})$ basic while soft-rot symptoms were not visible yet. Color of macerated tissues after $24 \mathrm{~h}$ of incubation and without addition of phenol red is shown as a control $(\mathbf{F})$.

plant might constitute a key event in the initial steps of the infectious process.

In summary, taking into consideration the diversity of products of the various Pel activities, $\mathrm{pH}$ control of Pel synthesis appears to be an efficient strategy, permitting E. chrysanthemi to adapt to continuous modifications of the physico-chemical environment while keeping infectious abilities at the optimum level. This reconciles both catalysis and regulatory hypotheses put forward to rationalize in ecological terms the increase of Pel repertoire by gene duplication.

The regulation of pel gene expression is a complex system involving multiple regulators and modes of regulation (Hugouvieux-Cotte-Pattat et al. 1996; Reverchon et al. 1998). However, identification of environmental conditions affecting pelA expression was an undocumented observation. Here, we obtained an acid pH-mediated activation of 17-fold (Fig. 1C). Unfortunately, we failed to identify the molecular regulator mediating $\mathrm{pH}$-dependent regulation in the known pel regulators, i.e., KdgR, Fur, and PecS. One of the next questions will be to know whether the same regulator mediates the induction under both acidic and basic conditions or whether each induction relies on a separate regulator. An important conclusion from the present work is that $\mathrm{pH}$ induction is a prerequisite for PGA induction to occur. This is reminiscent of the Agrobacterium tumefaciens VirA/VirG system, which mediates acetosyringone/sugars induction of the vir genes only in acidic conditions (Mantis and Winans 1992; Shimoda et al. 1990). An immediate hypothesis therefore is that E. chrysanthemi possesses a VirA/VirG-like system that regulates Pel synthesis. Ongoing studies aim at testing this hypothesis.

\section{ACKNOWLEDGMENTS}

We are grateful to the Erwinia groups in Lyon and Paris for providing us with bacterial strains. The contribution of Mohammed El Hassouni (University of Fès, Morocco), who initiated pH studies, should be acknowledged. Thanks are due to other members of the Erwinia group for discussion, and to V. Mejean, J. C. Patte, and J. DeMoss for careful reading of the manuscript. This work was supported by grants from the CNRS and the University of Aix-Marseille II, and a fellowship of the MENRT to L. N.

\section{LITERATURE CITED}

Baker, C. J., Atkinson, M. M., Roy, M. A., and Collmer, A. 1986. Inhibition of the hypersensitive response in tobacco by pectate lyases. Physiol. Mol. Plant Pathol. 29:217-225.

Baker, C. J., Mock, N., Atkinson, M. M., and Hutcheson, S. W. 1990. Inhibition of the hypersensitive response in tobacco by pectate lyase digests of cell wall and of polygalacturonic acid. Physiol. Mol. Plant Pathol. 37:133-167.

Barras, F., Thurn, K. K., and Chatterjee, A. K. 1987. Resolution of four pectate lyase structural genes of Erwinia chrysanthemi (EC16) and characterization of the enzymes produced in Escherichia coli. Mol. Gen. Genet. 209:319-325.

Barras, F., van Gijsegem, F., and Chatterjee, A. K. 1994. Extracellular enzymes and pathogenesis of soft-rot Erwinia. Annu. Rev. Phytopathol. 32:201-234.

Beaulieu, C., Boccara, M., and van Gijsegem, F. 1992. Pathogenic behavior of pectinase-defective Erwinia chrysanthemi mutants on different plants. Mol. Plant-Microbe Interact. 6:197-202.

Boccara, M., Diolez, A., Rouve, M., Kotoujansky, A., and Coleno, A 1988. The role of individual pectate lyases of Erwinia chrysanthemi strain 3937 in pathogenicity on Saintpaulia plants. Physiol. Mol. Plant Pathol. 33:95-104.

El Hassouni, M., Chambost, J. P., Expert, D., van Gijsegem, F., and Barras F. 1999. The minimal gene set member $m s r A$, encoding peptide methionine sulfoxide reductase, is a virulence determinant of the plant pathogen Erwinia chrysanthemi. Proc. Natl. Acad. Sci. USA 96:887892.

Franza, T., and Expert, D. 1991. The virulence-associated chrysobactin iron uptake system of Erwinia chrysanthemi 3937 involves an operon encoding transport and biosynthetic functions. J. Bacteriol. 173:68746881.

Franza, T., Sauvage, C., and Expert, D. 1998. Iron regulation and pathogenicity in Erwinia chrysanthemi 3937: Role of the Fur repressor protein. Mol. Plant-Microbe Interact. 12:119-128.

Grignon, C., and Sentenac, H. 1991. $\mathrm{pH}$ and ionic conditions in the apoplast. Annu. Rev. Plant Physiol. Plant Mol. Biol. 42:103-128.

Hugouvieux-Cotte-Pattat, N., Condemine, G., Nasser, W., and Reverchon, S. 1996. Regulation of pectinolysis in Erwinia chrysanthemi. Annu. Rev. Microbiol. 50:213-257.

Hugouvieux-Cotte-Pattat, N., Dominguez, H., and Robert-Baudouy, J. 
1992. Environmental conditions affect transcription of the pectinase genes of Erwinia chrysanthemi 3937. J. Bacteriol. 174:7807-7818.

López-Solanilla, E., Garcia-Olmedo, F., and Rodriguez-Palenzuela, P. 1998. Inactivation of the sapA to sapF locus of Erwinia chrysanthemi reveals common features in plant and animal bacterial pathogenesis. Plant Cell 10:917-924.

Mantis, N. J., and Winans, S. C. 1992. The Agrobacterium tumefaciens vir gene transcriptional activator VirG is transcriptionally induced by acid $\mathrm{pH}$ and other stress stimuli. J. Bacteriol. 174:1189-1196.

Masclaux, C., and Expert, D. 1995. Signalling potential iron plantmicrobe interactions: The pathogenic switch of iron transport in $\mathrm{Er}$ winia chrysanthemi. Plant J. 7:121-128.

Masclaux, C., Hugouvieux-Cotte-Pattat, N., and Expert, D. 1996. Iron is a triggering factor for differential expression of Erwinia chrysanthemi strain 3937 pectate lyases in pathogenesis of African violets. Mol Plant-Microbe Interact. 9:198-205.

Miller, J. H. 1972. Experiments in Molecular Genetics. Cold Spring Harbor Laboratory, Cold Spring Harbor, NY.

Perombelon, M. C. M., and Kelman, A. 1980. Ecology of soft-rot Erwinias. Annu. Rev. Phytopathol. 18:361-387.

Preston, J. F., III, and Rice, J. D. 1991. Kinetic analysis of pectate lyases by high-performance liquid chromatography. Carbohydr. Res. 215: 137-145.

Preston, J. F., III, Rice, J. D., Ingram, L. O., and Keen, N. T. 1992. Differential depolymerization mechanisms of pectate lyases secreted by Erwinia chrysanthemi EC16. J. Bacteriol. 174:2039-2042.

Py, B., Barras, F., Bouillant, S., Salmond, G., and Nasser, W. 1998. Extracellular enzymes and their role in Erwinia virulence. Pages $157-$ 168 in: Bacterial Pathogenesis: Methods in Microbiology. P. Williams, J. Ketley, and G. Salmond, eds. Academic Press, London.
Py, B., Loiseau, L., and Barras, F. 1999. Assembly of the type II secretion machinery of Erwinia chrysanthemi: Direct interaction and associated conformational change between OutE, the putative ATPbinding component, and the membrane protein OutL. J. Mol. Biol. 289:659-670.

Reverchon, S., Bouillant, M. L., Salmond, G., and Nasser, W. 1998. Integration of the quorum sensing system in the regulatory networks controlling virulence factor synthesis in Erwinia chrysanthemi. Mol. Microbiol. 29:1407-1418.

Reverchon, S., Nasser, W., and Robert-Baudouy, J. 1994. pecS: A locus controlling pectinase, cellulase and blue pigment production in $\mathrm{Er}$ winia chrysanthemi. Mol. Microbiol. 11:1127-1139.

Reverchon, S., and Robert-Baudouy, J. 1987. Regulation of expression of pectate lyase genes pelA, pelD, and pelE in Erwinia chrysanthemi. J. Bacteriol. 169:2417-2423.

Reverchon, S., van Gijsegem, F., Rouve, M., Kotoujansky, A., and Robert-Baudouy, J. 1986. Organisation of a pectate lyase gene family in Erwinia chrysanthemi. Gene 49:215-224.

Roy, C., Kester, H., Visser, J., Shevchik, V., Hugouvieux-Cotte-Pattat, N., Robert-Baudouy, J., and Benen, J. 1999. Modes of action of five different endopectate lyases from Erwinia chrysanthemi 3937. J. Bacteriol. 181:3705-3709.

Shimoda, N., Toyotoda-Yamamoto, A., Nagamine, J., Usami, S., Katayama, M., Sagakami, K., and Machida, Y. 1990. Control of expression of Agrobacterium vir genes by synergistic actions of phenolic signal molecules and monosaccharides. Proc. Natl. Sci. USA 87:6684-6688.

Tardy, F., Nasser, W., Robert-Baudouy, J., and Hugouvieux-Cotte-Pattat, N. 1997. Comparative analysis of the five major Erwinia chrysanthemi pectate lyases: Enzyme characteristics and potential inhibitors. J Bacteriol. 179:2503-2511. 